\title{
Conduta dos agentes comunitários de saúde diante de casos de violência familiar
}

\author{
The conduct of community health agents in cases of family violence
}

Conducta de los agentes comunitarios de salud ante casos de violencia familiar

Carla Emanuella Pereira Rodrigues de Lira ${ }^{1}$, Patrícia de Paula Alves Costa da Silva², Ruth França Cizino da Trindade ${ }^{3}$

\section{RESUMO}

Este estudo teve como objetivo identificar a conduta dos agentes comunitários de saúde (ACS) inseridos na Estratégia de Saúde da Família diante da suspeita ou detecção dos casos de violência familiar. Trata-se de pesquisa descritiva de natureza qualitativa realizada junto a ACS, utilizando entrevistas. Os dados foram submetidos à análise de conteúdo, o que resultou em duas categorias. A primeira se refere ao rastreamento da violência doméstica à mulher. Nela os agentes comunitários de saúde relatam as suspeitas ou a detecção de casos e a forma que estes assumiram. Na segunda categoria são referenciadas quais as condutas adotadas, emergindo as possibilidades de abordagens às vítimas e as limitações do serviço. Os resultados mostram que a violência doméstica é identificada pelos agentes comunitários de saúde, indicando a necessidade de estabelecer estratégias que contribuam para uma melhor atenção à mulher e para a prevenção da violência familiar.

Descritores: Pessoal de Saúde; Violência Doméstica; Violência contra a Mulher; Programa Saúde da Família.

\section{ABSTRACT}

The objective of this study was to identify the conduct of community health agents (CHA) of the Family Health Strategy in cases of suspected or confirmed family violence. This qualitative, descriptive study was performed by interviewing $\mathrm{CHAs}$. The content analysis of the data revealed two categories. The first refers to tracking domestic violence against women. In this category, community health agents reported suspected or confirmed cases and their form. The second category consists of reports regarding the conducts that were adopted, revealing the possible approaches used with victims and the limitations of the service. Results showed that community health agents identify domestic violence, thus indicating the need to establish strategies that contribute with improving women's care and preventing family violence.

Descriptors: Health Personnel; Domestic Violence; Violence Against Women; Family Health Program.

\section{RESUMEN}

Estudio que objetivó identificar la conducta de agentes comunitarios de salud (ACS) desempeñándose en la Estrategia Salud de la Familia ante la sospecha o detección de casos de violencia familiar. Investigación descriptiva, cualitativa, realizada junto a Agentes Comunitarios de Salud, utilizándose entrevistas. Datos sometidos a análisis de contenido, resultando dos categorías. La primera se refiere al rastreo de la violencia doméstica a la mujer. En ella, los Agentes Comunitarios de Salud informan las sospechas o la detección de casos y la forma que dichos casos asumen. En la segunda categoría son explicitadas las conductas adoptadas, emergiendo las posibilidades de abordaje a las víctimas y las limitaciones del servicio. Los resultados demuestran que la violencia doméstica es identificada por los Agentes Comunitarios de Salud, indicando la necesidad de establecer estrategias que contribuyan a una mejor atención de la mujer y a la prevención de la violencia familiar.

Descriptores: Personal de Salud; Violencia Doméstica; Violencia contra la Mujer, Programa de Salud Familiar.

\footnotetext{
${ }^{1}$ Enfermeira. Maceió, AL, Brasil. E-mail: carlaemanuellap@yahoo.com.br.

${ }^{2}$ Enfermeira. Discente do Programa de Pós-Graduação em Enfermagem da Universidade Federal de Alagoas (UFAL), nível Mestrado. Maceió, AL, Brasil. E-mail: ppalvescosta@hotmail.com.

${ }^{3}$ Enfermeira, Doutora Enfermeira. Professora Adjunto da UFAL. Maceió, AL, Brasil. E-mail: ruth trindade@yahoo.com.br.
} 


\section{INTRODUÇÃO}

A violência contra a mulher é fenômeno universal que atinge todas as classes sociais, etnias, religiões e culturas, ocorrendo em populações de diferentes níveis de desenvolvimento econômico e social.

As disparidades de gênero colocam as mulheres em desvantagem em relação aos homens. A violência de gênero engloba a violência praticada por homens contra mulheres e vice-versa, embora as mulheres sejam as maiores vítimas deste tipo de violência gerada pelas desigualdades entre os sexos ${ }^{(1)}$.

Estas desigualdades surgem desde a educação das crianças e são perpetuadas por adultos de ambos os sexos ${ }^{(2)}$. Tal processo não se restringe aos países menos desenvolvidos; pelo contrário, é um fenômeno complexo, milenar que perpassa civilizações e sistemas econômicos ${ }^{(3)}$.

Apesar de o espaço familiar ser privado, e dessa forma, considera-se que os fatos que nele ocorrem não dizem respeito à sociedade e às autoridades, com o surgimento dos movimentos sociais, inclusive do movimento de mulheres, alguns temas do espaço doméstico foram trazidos a público e são hoje objeto de debate social e intervenção do Estado(2).

A violência intrafamiliar é descrita como toda ação ou omissão que prejudique o bem-estar, a integridade física, psicológica ou a liberdade e o direito ao pleno desenvolvimento de um membro da família. Este tipo de violência é considerada mesmo quando praticada fora do domicílio da vítima, quer tenha sido ocasionada pelos pais biológicos ou por pessoas que exerçam a função parental. Conforme encontrado na literatura, a maioria dos casos de violência acontece no próprio domicílio, afetando principalmente crianças, mulheres e idosos, podendo gerar não só na vítima, mas em toda a sua família traumas marcantes durante toda a vida ${ }^{(4)}$.

Os efeitos da violência podem ser sérios para a saúde reprodutiva feminina e aumentam o risco de inúmeros outros problemas de saúde a longo prazo, resultando em dores crônicas, doenças mentais, doenças sexualmente transmissíveis, gravidez indesejada e alterações do comportamento como desordens alimentares e do sono ${ }^{(5)}$.

Em virtude disso, os profissionais de saúde precisam estar atentos aos sinais de alerta emitidos pelas mulheres que procuram os serviços, os quais podem ser indicativos de violência. Elas quase sempre omitem os acontecimentos, mas recorrem aos serviços para tratar de suas lesões e cabe a estes - sabendo da dimensão do fenômeno em nosso país - encontrarem meios de investigar melhor a situação(2).

A Estratégia Saúde da Família (ESF) se apresenta como a nova maneira de trabalhar a saúde, tendo a família como centro de atenção, facilitando a aproximação e a criação de vínculos entre profissionais e pessoas $^{(6)}$. Assim a ESF surge como grande aliada na assistência às mulheres vítimas de violência familiar, alicerçando a construção de um fluxo de referência e contra-referência. $O$ vínculo que os profissionais desse modelo de atenção constroem com a comunidade aproxima-os de cada integrante das famílias, criando um espaço de acolhimento e confiança para as usuárias relatarem situações de violência vividas em casa. Serviços de atenção à saúde, nos quais há a fragmentação do indivíduo em relação ao seu contexto, enfrentariam mais obstáculos para tomar conhecimento do problema, retardando a detecção do mesmo.

Neste contexto, esta pesquisa teve como objeto o estudo sobre conduta adotada por agentes comunitários de saúde (ACS), diante de casos de violência familiar contra a mulher, cujo objetivo foi identificar a conduta dos agentes comunitários de saúde inseridos na ESF, diante da suspeita ou detecção dos casos de violência familiar.

\section{METODOLOGIA}

Pesquisa descritiva de natureza qualitativa, realizada em Unidades das ESF na cidade de Maceió, capital do Estado de Alagoas. Estas unidades de saúde da família alocam as equipes de ESF que são compostas por profissionais médicos, enfermeiros, auxiliares de enfermagem e agentes comunitários de saúde.

A ESF em Maceió é composta por 72 equipes de saúde da família distribuídas em 35 USF instaladas nas regiões periféricas da cidade. Para a escolha das equipes em que os agentes de saúde seriam selecionados, utilizamos sorteio com elaboração de uma lista das equipes. Desta forma foram sorteadas inicialmente sete equipes, mas devido às características da pesquisa qualitativa, foram entrevistados agentes de saúde de cinco unidades.

Os sujeitos do estudo foram constituídos por 13 ACS que trabalham nessas unidades e o número de 
participantes foi definido pela saturação teórica a partir da convergência dos achados ao objetivo proposto nesta pesquisa. A escolha pelos ACS se deu pelo fato dos mesmos serem considerados importantes na implementação do Sistema Único de Saúde (SUS), especialmente por fortalecer a Atenção Básica ${ }^{(7)}$, além de em seu trabalho apresentarem uma ligação com a realidade da comunidade, o que possibilita o fortalecimento do vínculo entre profissionais e sujeitos $^{(8)}$.

As informações foram coletadas por meio de entrevistas registradas em gravação, durante o segundo semestre de 2010, sendo utilizadas duas perguntas desencadeadoras: Durante o atendimento a uma usuária, você suspeitou de situação de violência vivida por ela? Qual a atitude que você adotou ou adotaria diante dessa suspeita? Depois de colhidas, procedeu-se à escuta e transcrição cuidadosas, organizadas, buscando encontrar núcleos de sentido, que sendo aproximados originaram as categorias e respectivas subcategorias.

Foram feitos registros de campo que contribuíram para a análise das informações, permitindo o despertar de um olhar crítico sobre as condições físicas em que trabalham os ACS das ESF selecionadas para a pesquisa, observar a atuação dos mesmos desde o momento do primeiro contato para a participação na pesquisa até a efetivação da entrevista, atentando para os detalhes do tom de voz, expressão facial e movimento corporal.

Com o objetivo de manter o sigilo dos sujeitos, as unidades onde foram realizadas a pesquisa não foram identificadas e todos os entrevistados identificados por ordem numérica para a total preservação da identidade.

A escuta, transcrição e leitura das entrevistas, permitiu uma aproximação às convergências das falas dos entrevistados, cujo resultado foi submetido à análise de conteúdo categorial, conforme os pressupostos de Laurence $\operatorname{Bardin}^{(9)}$. As entrevistas foram inventariadas e agrupadas de acordo com o tema e núcleo de significação das palavras entre as unidades de análise, tendo emergido duas categorias: rastreamento da violência doméstica à mulher, e a violência familiar à mulher: comportamento dos ACS.

Os profissionais foram esclarecidos quanto aos aspectos relacionados no Termo de Consentimento Livre e Esclarecidos (TCLE) seguindo as normas da Resolução 196/96 e assinaram o TCLE em duas vias, uma entregue a eles e outra, ficando sob posse das pesquisadoras. Esta pesquisa foi aprovada pelo CEP/UFAL com protocolo $n^{\circ}$ 010304/2009-72.

\section{RESULTADOS E DISCUSSÃO}

Frente à interpretação das informações, emergiram duas categorias, com subcategorias: categoria 1: Rastreamento da Violência doméstica à Mulher. Abrange duas subcategorias: Suspeita e/ou detecção de casos de violência doméstica à mulher e formas de violência doméstica à mulher e a segunda categoria foi - Violência Familiar à Mulher: comportamento dos ACS que compreende também duas subcategorias: possibilidades de abordagem às vítimas e limitações do serviço.

A pesquisa revelou que a violência doméstica que está presente em nossa sociedade, também está presente nas unidades de saúde, pois os relatos dos ACS mostram que ela é visível, o que exige conhecimento e preparo que os mesmos revelam não ter. Esta situação dificulta que a ação destes profissionais possa apoiar, encaminhar e/ou orientar as mulheres vitimas de violência doméstica.

\section{Rastreamento da Violência Doméstica à Mulher}

Nesta categoria podemos observar que a partir do rastreio da violência doméstica praticada contra mulher, encontramos nas falas dos ACS um delineamento de duas subcategorias que se configuraram como sendo a suspeita ou a própria detecção de casos e as formas que estes assumiram. Estes não se caracterizando somente por aquilo que foi visível como nas agressões com lesões corporais, mas naquelas que não eram visíveis aos olhos, entretanto percebidas pelos ACS.

Desta forma tornou-se imprescindivel rastrear a violência contra as mulheres uma vez que é um fenômeno que tem suas raízes nas desigualdades de gênero, traduzidas em relações assimétricas de poder e, ainda, que esse poder seja relacional, a realidade tem revelado que ele muito dificilmente beneficia as mulheres, que são alvo majoritariamente preferencial da violência de gênero ${ }^{(10)}$.

Por este motivo, ampliar investigações e aprofundar a discussão sobre esse fenômeno da realidade possibilitará uma melhor compreensão e visibilidade do problema, além de oferecer subsídios para que políticas públicas e a atuação dos profissionais nos Serviços de Saúde valorizem estratégias para o empoderamento das 
mulheres, possibilitando, assim, rupturas das amarras da submissão(11).

\section{Suspeita e/ou detecção de casos de violência doméstica à mulher}

Essa subcategoria evidencia que os entrevistados tiveram a oportunidade de se depararem com a mulher em situação de violência doméstica, seja através da suspeita ou mesmo da própria detecção das agressões. Assim constatamos nesta pesquisa que, de um modo geral, a violência é reconhecida pelos participantes.

Desta forma é possível solidificar a ideia de que os ACS têm assumido diferentes atividades na produção de atos em saúde utilizando ao mesmo tempo seus saberes e modos de agir no controle das causas, além dos fatores de risco individual e coletivo em diferentes sistemas e contextos $^{(12)}$.

Tal situação pode ser encontrada durante o atendimento individual ou visitas domiciliares, outras já são relatadas pela própria comunidade aos ACS como nas falas a seguir:

\section{Já presenciei, já intervi e já orientei (ACS-1).}

[...] eu já suspeitei, não cheguei a ver e tudo, mas simplesmente cheguei lá, tava com hematoma [...] depois os vizinhos me relatam que a mulher apanha, que o marido bebe, que toma droga (ACS-2).

Essas citações ilustram o que mais pôde ser evidenciado durante a pesquisa, ou seja, que a suspeita de agressões se mesclam e se tornam rotineiras na prática profissional, podendo correr o risco de serem banalizadas pela falta de atitude profissional ou de preparo para lidar com a situação. A violência conjugal citada pela entrevista é encontrada em outros grupos de mulheres, estando relacionada ao uso abusivo de álcool, comportamentos permissivos ao homem, e contra os quais as mulheres não encontram apoio para lutar contra eles $^{(13)}$.

Uma das participantes chega a citar que o acontecimento já é normal em sua área de atuação:

De vez em quando é normal. Aparece, de vez em quando, na área onde eu trabalho [...] Às vezes você vê um olhinho roxo, um arranhãozinho aqui, um apertão no braço (ACS3).
Dá pra perceber que a problemática chega a ser identificada, mas descrevê-la como "normal" leva a pensar se o fato está sendo banalizado ou, não está sendo interpretado como sendo desnecessário qualquer tipo de intervenção. Por isso, repensar qual é o papel que os ACS exercem na prevenção da violência praticada contra a mulher pode encontrar caminhos para promover um atendimento de qualidade, com o objetivo de promover a saúde da mulher, procurando colocar a questão da violência doméstica, que está tão presente em nossa sociedade, nas ações de atenção à saúde.

O enfoque na atenção primária se justifica por ser este um local privilegiado para o desenvolvimento de ações de prevenção, reflexão e orientação sobre o tema, pois tem uma grande cobertura e possibilita um contato mais estreito com as mulheres, podendo reconhecer e acolher o caso antes de incidentes mais graves ${ }^{(14)}$. Mas não foi em todas as falas desta pesquisa que uma atitude de intervenção foi adotada.

\section{Formas de violência doméstica à mulher}

Essa subcategoria mostra que os ACS detectaram diferentes formas de violência contra a mulher. Algumas se revelaram não apenas no visível, como no caso dos hematomas, mas também no que estava invisível às condições físicas das vítimas. O invisível refere-se ao medo que vai tornando a mulher sem reação ou a um longo período envolvendo movimentos corporais e mensagens subliminares, usados pelo agressor, para manter a vítima sob controle.

Deste modo a violência doméstica representa toda ação ou omissão que prejudique o bem-estar, a integridade física, psicológica ou a liberdade e o direito ao pleno desenvolvimento. Agressões físicas, verbais, emocionais, sexuais, econômica, ameaças, privações foram os tipos de violências detectadas e configuradas pelos integrantes desta pesquisa. Isso nos levou a acreditar que eles não só levam em consideração a violência física, mas, também, os outros tipos de violência que podem ser praticados e essas formas são identificadas pelos ACS como podemos ler nas falas abaixo:

Tipo, uma citologia, tem paciente minha que não pode fazer porque o marido não deixa. Pra mim, isso é um tipo de violência também, porque uma citologia é um preventivo pra toda mulher, tem que fazer (ACS-4) 
Tem caso que a mulher não quer manter relação sexual, que o homem pega apulso mesmo, dentro de casa, pega mesmo! (ACS-5).

Um estudo realizado no município do Rio de Janeiro(14) evidencia que o Ministério da Saúde e diversas organizações não-governamentais feministas têm produzido material didático e treinamentos aos profissionais de saúde de modo que eles possam identificar, apoiar e dar o devido encaminhamento às vítimas de violência. Um avanço já pode ser percebido no que tange ao enfrentamento da violência sexual pelos serviços de saúde. Tais medidas resultam tanto da compreensão de que a violência representa uma violação dos direitos humanos, como também do reconhecimento de que esta é uma importante causa do sofrimento e adoecimento, sendo fator de risco para diversos problemas de saúde físicos e psicológicos.

Apesar desses avanços, o estudo supracitado afirma ainda que os serviços de saúde nem sempre oferecem uma resposta satisfatória para o problema, que acaba diluído entre outros agravos ${ }^{(15)}$. Um estudo constatou que as mulheres atendidas por uma unidade de ESF percebem a violência que sofrem e se queixam de falta de liberdade e se ressentem pela atitude do companheiro, que as trai e também as agride ${ }^{(13)}$.

Traumatismos físicos foram corriqueiros e relatados durante a realização das entrevistas:

[...] a gente vê, fulana, o que foi isso no rosto? Umas, de imediato, diz que é queda né;

depois a gente vai comprando, comprando, e sabe que foi "bombaço" que levou (ACS-6).

[...] por várias vezes, não na frente dele né, ela (a usuária) já me relatou que ele quando está em crise agride ela, bate até a cabeça na parede (ACS-7).

O que acaba de ser exposto é da maior relevância, pois as marcas corporais são possíveis sinalizadoras da agressão(15).

Compreendem-se os agravos físicos como sendo decorrentes do trauma genital, evidenciado por lacerações, hematomas, equimoses e edemas, principalmente nas mulheres de maior idade, e nos casos das crianças vitimizadas, que podem ainda apresentar lesões na vagina, no períneo, no ânus e no reto. Já nos casos de lesões extragenitais, encontram-se escoriações, equimoses e fraturas da face ${ }^{(16)}$.

As políticas de proteção e segurança são essenciais para o enfrentamento à violência, mas é preciso avançar tanto em políticas de prevenção, como citado anteriormente, mas numa assistência além da tecnicista, que esteja associado à sensibilidade humana e a subjetividade dessa relação, reconhecendo a mulher como um ser único em suas singularidades ${ }^{(16)}$.

\section{Violência familiar à mulher: comportamento dos ACS}

Nesta categoria, podemos observar que os ACS adotam posturas diversificadas diante da suspeita ou mesmo a detecção de casos de violência doméstica contra as mulheres. Por este motivo surgiu a subcategoria possibilidades de abordagem às vítimas, evidenciando que apesar das especificidades de cada caso, não se trabalha com um caminho que direcione o ACS.

Acrescentando-se ao fato da inexistência de um protocolo que ajude o profissional de alguns serviços de saúde a encontrar a forma mais eficaz para o atendimento à mulher vítima de violência, surgiu a outra subcategoria que são as limitações do serviço. Esta trata da precariedade de recursos que as ESF possuem para enfrentar a problemática que esta pesquisa discute.

Apenas em uma unidade da EFS as pesquisadoras observaram a presença de um protocolo de encaminhamento anexado em mural para as mulheres vítimas de violência. $O$ que chamou atenção foi o fato de os entrevistados desconhecerem este protocolo dentro do seu próprio local de trabalho. Tal fato nos levou a uma segunda constatação: a de que os profissionais necessitam ser informados quanto aos mecanismos que possuem para auxiliarem as vítimas. Рara isso é necessário haver treinamentos com as equipes, que as mesmas saibam onde estão e quais os mecanismos de apoio que o Estado e o município disponibilizam para as vítimas de violência, pois é importante para a confiança entre o profissional e a vítima que ela encontre resolutividade para a situação em que vive.

Se todos os profissionais podem ser divulgadores de direitos humanos e da rede intersetorial que presta apoio à violência, e também provê trabalho, moradia, creche, escola, que são todos elementos fundamentais para a emancipação e uma vida livre de violência, os ACS encontram-se na específica situação de acesso e relação 
diferenciada frente às questões do domicílio e da vida comunitária das/dos usuárias/usuários do serviço. Ao contrário do que vem acontecendo em alguns programas e unidades, os ACS não deveriam ter papel central na detecção e orientação e assistência dos casos, já que a sua proximidade com a comunidade os coloca em posição de maior risco de quebra de sigilo e vulnerabilidade à própria violência(17).

\section{Possibilidades de abordagem às vítimas}

Como dito anteriormente, as posturas de abordagens às vítimas ou diante de uma possível situação de violência foram diversificadas. Alguns profissionais adotam a conduta de trazer o caso para que a unidade, enquanto equipe, tome conhecimento:

\section{[...] Eu traria pra unidade até porque a gente tomar pra} gente sozinha é complicado, é muito complicado você agir só [...] Então eu traria pra unidade e a unidade enquanto equipe é que resolveria isso. Agora tomar a frente sozinha...(ACS-8)

Nas unidades em que dispunham de assistente social, todos os profissionais relataram que seria para esta profissional que encaminhariam:

Eu ia falar pra assistente social porque a gente tem o suporte dela. Mas sempre ela vai. Quando acontece alguma coisa, ela sempre vai com a gente. E aí ela ia partir pra outros meios (ACS-9).

Nessas unidades os profissionais afirmaram desconhecerem outros meios de conduta, senão o de levar o caso para a assistente social:

Vale ressaltar que boa parte das equipes de saúde da família contam apenas com as categorias que compõem a equipe básica, médico, enfermeiro, auxiliar/técnico de enfermagem e o ACS. Nas equipes onde não havia a presença da assistente social, os profissionais abordariam a vítima no sentido de lhes prestar apoio emocional, encaminhá-la para os órgãos responsáveis nessa temática. Entretanto todas estas atitudes foram colocadas de forma hipotética, mostrando não existir nas unidades de ESF nenhum protocolo estabelecido sobre a conduta a ser feita, caso houvesse algum caso de violência detectado, o que pode significar que em situações como as citadas na primeira categoria nenhuma atitude concreta foi tomada.

Um estudo(18) mostra que, por sua magnitude, o enfrentamento da violência doméstica contra a mulher não pode mais se limitar a ações isoladas, pautadas na linearidade, que por si só não dão conta da complexidade do fenômeno. Fazem-se necessárias ações intersetoriais e interdisciplinares que propiciem o trabalho colaborativo e, dessa forma, a promoção de uma assistência menos passiva. Nessa perspectiva, o enfrentamento da violência exige a articulação efetiva entre diferentes setores: saúde, segurança pública, justiça e trabalho, assim como requer o envolvimento da sociedade civil organizada em redes integradas de atendimento.

A ACS- 1 expressa o seu apoio à vítima relatando que:

Passo o tempo que tenho que passar na casa (realizando a visita domiciliar de rotina) e depois fico só conversando mesmo entendeu?! Desabafam (as vitimas) mesmo assim, me contam tudo [...].

Duas agentes referem que fariam encaminhamento para os órgãos responsáveis:

[...] acionar a Delegacia da Mulher, teria que ver até onde foi essa violência e acionar os órgãos (ACS-10).

[...] encaminhar as vítimas, tantos os adolescentes como as mulheres, para o CAV CRIME. Aí no caso o que eu poderia fazer era isso: enviar pra lá (ACS-11).

O Centro de Apoio às Vítimas de Crime (CAV Crime) consiste em um Programa Federal da Subsecretaria de Direitos Humanos da Secretaria da Presidência da República. O Governo do Estado de Alagoas, por intermédio da Secretaria Coordenadora de Justiça e Defesa Social, e da Secretaria Especializada de Direitos Humanos, estabeleceu uma parceria, inaugurando em novembro de 2001, o CAV Crime. As principais ações visam acolher e orientar toda e qualquer vítima de crime e prestar assistência jurídica, psicológica e social, respeitando a cidadania e os Direitos Humanos(19).

Apesar do grave impacto da violência à saúde física e mental de mulheres, ainda há resistência e necessidade de maior preparo para abordar situações de violência de gênero e em lidar com as pessoas vitimizadas no âmbito 
do sistema de saúde. Em uma das falas, o ACS-3 prefere omitir a situação que encontra, pois a considera de ordem privada:

Você tenta chegar junto, mas aquele negócio né: briga de marido e mulher não se mete

a colher! (ACS-3).

Os achados apresentados corroboram com alguns encontrados em pesquisa realizada na cidade de Recife Pernambuco há quase 10 anos, a qual visava avaliar a implementação do Programa de Assistência Integral à Saúde da Mulher - PAISM. Nesta, foram entrevistados profissionais de diferentes categorias de saúde acerca das questões abordadas pelo PAISM.

Em relação às questões da violência doméstica e sexual, o discurso revelou a insegurança que os profissionais sentiam em atuar e o medo de intervir nessas situações consideradas de ordem privada. Suas condutas restringiram-se a encaminhar a mulher para apoio psicológico ou para a Delegacia da Mulher, em caso de agressão física(20).

Nesse sentido e no percurso desta pesquisa, pôde ser evidenciado o quanto os profissionais necessitam de informações concretas e bem sedimentadas com relação à qual postura adotar.

\section{Limitações do serviço}

Inúmeras justificativas foram dadas para não haver a devida continuidade do caso, dentre elas estão, principalmente, o medo de se expor, não consentimento para intervir, insegurança e o despreparo no manejo das vítimas. A totalidade dos entrevistados concluiu suas entrevistas deixando registrado que sentem a imensa necessidade de serem capacitados para lidarem com as questões de violência doméstica à mulher.

Desde que a gente chegou aqui (para trabalhar na unidade) não tivemos nenhuma capacitação, a não ser do câncer infantil. Então a gente teria mais a dar pra eles se a gente tivesse uma capacitação, um apoio melhor da Secretaria (ACS-12).

[...] deveriam orientar como eu devo agir, aonde é que eu deveria buscar ajuda até pra eu poder orientar essa pessoa, no caso, a que está sendo violentada (ACS-13).
Mas esta não foi a única realidade encontrada, infelizmente há deficiências na resolutividade:

[...] mesmo que a gente faça alguma coisa, é muito difícil chegar ajuda desse tipo assim [...] ter respaldo, que nós não temos (ACS-2).

Há também deficiências com relação ao conhecimento dos instrumentos legais. A grande maioria afirmou apenas conhecer a Lei Maria da Penha, mas mesmo assim não chegou a ler a mesma na íntegra, muito menos conhecer outros dispositivos legislativos. $O$ ACS-9 representa a voz de todos os participantes ao afirmar que:

Conheço só a lei da Maria da Penha e só de falar na televisão (ACS-9).

De fato a Lei $n^{\circ} 11.340$ de 07/08/2006(21), a conhecida Lei Maria da Penha, teve e tem bastante repercussão nos meios de comunicação. Porém, este instrumento é apenas o mais recente do arcabouço legal concernente à temática da violência à mulher.

Os Códigos de Ética dos profissionais de saúde são bem mais antigos e já fazem, implicitamente, referência a esse tema.

Através da realização desta pesquisa, foi notório que o setor saúde, por ser um dos espaços privilegiados para a detecção das mulheres vítimas de violência, tem papel importantíssimo na articulação dos serviços e organizações, que atendem direta ou indiretamente situações sobre este conteúdo. Os cursos da área da saúde, e no nosso caso o curso de enfermagem, não podem se isentar de discutir em seus currículos a questão da violência, situação presente em nossa sociedade em diversas formas.

Os gestores municipais e estaduais também têm papel decisivo na organização de redes integradas de prestação de atendimento, na capacitação de recursos humanos, na provisão de insumos e na divulgação para o público em geral.

Entende-se desta forma que a violência contra a mulher deve ser vista como uma questão de saúde pública que precisa de intervenções sedimentadas, ou seja, de políticas públicas específicas. A Estratégia Saúde da Família deve ser vislumbrada como uma política que 
tem grande potencial para o combate desta problemática.

\section{CONCLUSÃO}

Baseado na importância que a violência doméstica e a violência contra a mulher tem para o cuidado à saúde das pessoas, somando a isso a possibilidade que a ESF tem para a atenção à saúde e a importância que a atuação dos ACS tem neste contexto, é que constatamos a importância deste estudo sobre a conduta dos mesmos diante de casos de violência familiar contra a mulher, pois poderá provocar reflexões sobre a prática dos ACS e a necessidade de capacitações, treinamento para que melhor desempenhem suas funções.

Constatamos no estudo que a violência vivida por mulheres atendidas por unidades da ESF é percebida pelo ACS em suas diversas formas de manifestação, mas apesar desta realidade, o serviço não os prepara para agir de forma propositiva junto a estas mulheres.

É possível perceber a riqueza de conteúdos existente nas falas dos participantes superando todas as expectativas das pesquisadoras. $O$ que chamou a atenção foi o fato de os profissionais da ESF, apesar do medo e da insegurança que sentem, parecerem abertos para relatar sobre o assunto. Essa característica nos sugere que a violência contra a mulher é um problema que também está presente no cotidiano dos trabalhadores das unidades.

Outra característica marcante é que a maioria absoluta dos entrevistados relata que é uma temática bastante difícil de lidar, uma vez que se sentem despreparados e sem proteção e segurança, além da angústia de se depararem com a demora na resolutividade. Fato que contribui ainda mais para o aumento e invisibilidade dos casos.

\section{REFERÊNCIAS}

1. Saffioti HIB. Gênero, patriarcado, violência. 1st ed. São Paulo: Fundação Perseu Abramo, 2004.

2. Portella AP. Abordagem social sobre violência e saúde das mulheres. Jornal da Rede Feminista de Saúde [Internet]. 2000; (22):33-38. Available from: http://www.redesaude.org.br/Homepage/JornaldaRede/JR22/Jorna l\%20da\%20Rede\%20n\%BA\%2022.pdf

3. Oliveira MAB. Mulher e violência em Maceió: um pensar sobre sua história [dissertation]. Maceió: Ichca/UFAL, Alagoas; 2006. 123p. 4. Oliveira MT, Samico I, Ishigami ABM, Nascimento RMM. Violência intrafamiliar: a experiência dos profissionais de saúde nas Unidades de Saúde da Família de São Joaquim do Monte, Pernambuco. Rev
Por outro lado, ao comparar o comportamento dos ACS, no que se refere à violência contra a mulher, percebeu-se que as condutas são distintas, as visões se opõem. Apesar disso, todos se mostraram abertos às possíveis capacitações e treinamentos, uma vez que vislumbram nos mesmos, a possibilidade de prepará-los para um enfrentamento mais efetivo e interdisciplinar. Chegam até a solicitar da equipe de pesquisadoras e da Secretaria Municipal de Saúde o apoio necessário para a realização de palestras nas unidades da ESF, na comunidade e nas escolas.

A sociedade toda tem discutido sobre a violência, mas o que encontramos é que a mesma avança. Assim consideramos que é preciso interromper a dinâmica de construção da violência doméstica como algo natural, que pertence ao homem ou a mulher e por isso não se deve intervir.

Estamos em um momento em que a assistência à saúde aumenta a sua abrangência e acesso com as equipes de ESF, desta forma acreditamos na necessidade de enfrentamento do problema na esfera das políticas públicas, incluindo a atuação dos serviços de saúde, pois a violência é considerada atualmente como um problema de saúde pública, mas parece que os profissionais que estão na ponta do sistema não estão participando desta discussão e desconhecem o papel que devem exercer necessitando de participarem mais ativamente neste processo, pois as mulheres vítimas de violência são usuários destes serviços.

Neste contexto, espera-se oportunizar a discussão em torno dos resultados desta pesquisa, contribuindo para a prevenção de violência familiar à mulher, ampliação de estratégias políticas voltadas para o tema, amplas campanhas, em nível nacional, para a prevenção e controle da violência familiar contra as mulheres, capacitação dos profissionais da saúde, dentre outros.

Bras Epidemiol [Internet]. 2012 [cited 2012 abr 27]; 15(1): 166-78 Available from: http://www.scielo.br/pdf/rbepid/v15n1/15.pdf 5. Larsen $\mathrm{KH}$, kruse M. Violence against women and consequent health problems: a register-based study. Copenhagen. Scand J Public Health, 2003; (31): 51-7.

6. Rosa WAG, Labate, R C. Programa Saúde da Família: a construção de um novo modelo de assistência. Revista Latino-Americana de Enfermagem [Internet]. 2005 [cited 2012 jan 15]; 13(6):1027-1034. Available from: www.scielo.br/pdf/rlae/v13n6/v13n6a16.pdf

7. Costa EM, Ferreira DLA. Percepções e motivações de agentes comunitários de saúde sobre o processo de trabalho em Teresina, Piauí. Trab. educ. saúde [Internet]. 2011 [cited 2012 jan 15]; 
9(3):461-478. Available from:

http://www.scielo.br/pdf/tes/v9n3/v9n3a07.pdf

8. Seone AF, Fortes PAC. A percepção do usuário do Programa Saúde da Família sobre a privacidade e a confidencialidade de suas informações. Saúde e Sociedade, São Paulo [Internet]. 2009 [cited 2012 jan 15];18(1):42-49. Available

from: www.scielo.br/pdf/sausoc/v18n1/05.pdf

9. Minayo MCS. O Desafio do conhecimento: pesquisa qualitativa em saúde. 8ed. São Paulo: Hucitec; 2004.

10. Fonseca RMGS, Leal AERB, Skubs T, Guedes RN, Egry EY.

Violência doméstica contra a mulher na visão do agente comunitário de saúde. Rev Latino-am Enfermagem. [Internet]. 2009 [cited 2012 abr 26]; 17(6): 974-980. Available from: http://www.scielo.br/pdf/rlae/v17n6/pt_08.pdf

11. Guedes RN, Silva ATMC, Coelho EAC. Violência conjugal: problematizando a opressão das mulheres vitimizadas sob olhar de gênero . Rev. Eletr. Enf. [Internet]. 2007 [cited 2010 mar 20];9(2):362-78. Available from:

http://www.fen.ufg.br/revista/v9/n2/v+9n2a06.htm

12. Oliveira AR, Chaves AEP, Nogueira JA, Sá LD, Collet N. Satisfação e limitação no cotidiano de trabalho do agente comunitário de saúde. Rev. Eletr. Enf. [Internet]. 2010 [cited 2012 jan 15];12(1):28-

36. Available

from: http://www.fen.ufg.br/revista/v12/n1/v12n1a04.htm

13. Trindade RFC, Almeida AM, Rozendo CA. Infidelidade masculina e violência domêstica: vivência de um agrupo de mulheres. Ciencia y Enfermeria. 2008 [cited 2012 jan 15]; 14(2):39-46.

14. Borsoi TS, Brandão ER, Cavalcanti MLT. Ações para o

enfrentamento da violência contra a mulher em duas unidades de atenção primária à saúde no município do Rio de Janeiro. Interface (Botucatu) [Internet]. 2009 [cited 2012 abr 26]; 13(28):165-174. Available from:

http://www.scielo.br/pdf/icse/v13n28/v13n28a14.pdf 15. Viera LB, Padoin SMM, e Landerdahl MC. A percepção de profissionais da saúde de um hospital sobre a violência contra as mulheres. Rev. Gaúcha Enferm. [internet]. 2009 [cited 2012 abr 27]; 12(4):609-616. Available from:

http://www.scielo.br/scielo.php?script=sci_arttext\&pid=S198314472 009000400005\&lng=pt\&nrm=iso

16. Morais SCRV, Monteiro CFS, Rocha SS. O cuidar em enfermagem à mulher vítima de violência sexual. Texto Contexto Enferm [Internet]. 2010 [cited 2012 abr 26]; 19(1): 155-60. Available from: http://www.scielo.br/pdf/tce/v19n1/v19n1a18.pdf

17. Lucas OAFP, Blima SL, Heloisa H, Julia D. Atenção integral à saúde de mulheres em situação de violência de gênero - uma alternativa para a atenção primária em saúde. Ciênc. saúde coletiva [Internet]. 2009 [cited 2012 abr 26]; 4(4):1037-1050. Available from: http://redalyc.uaemex.mx/src/inicio/ArtPdfRed.jsp?iCve=630116920 $\underline{06}$

18. Gomes NP, Diniz NMF, Filho CCS, Santos JNB. Enfrentamento da violência doméstica contra a mulher a partir da interdisciplinaridade e intersetorialidade. Rev. enferm. UERJ [Internet]. 2009 [cited 2012 abr 26]; 17(1):14-7. Available from:

http://www.revenf.bvs.br/pdf/reuerj/v17n1/v17n1a03.pdf

19. Secretaria Especializada da Mulher [Internet]. Centro de apoio às vítimas de crime. Maceió: Governo do Estado de Alagoas [cited 2010 feb 27]. Available from:

http://www.mulherecidadania.al.gov.br/cavcrime/institucional/ocentro-de-apoio-as-vitimas-de-crime

20. Franch M, Batista C, Camurça S. Ajuste estrutural, pobreza e desigualdades de gênero. Um caderno feminista de informação e reflexão para organizações de mulheres. - Recife, Iniciativa de Gênero/SOS Corpo Gênero e Cidadania, 2001.

21. Diário Oficial da União. Lei 11.340 (BR) de 7 de agosto de 2006. Cria mecanismos para coibir a violência doméstica e familiar contra a mulher, nos termos do $8^{\circ}$ do art. 226 da Constituição Federal. Brasília (Brasil): Diário Oficial da União; 2006.

Artigo recebido em 23/10/2010.

Aprovado para publicação em 25/01/2012.

Artigo publicado em 31/12/2012. 